\title{
Splenic Trabecular Vein
}

National Cancer Institute

\section{Source}

National Cancer Institute. Splenic Trabecular Vein. NCI Thesaurus. Code C49779.

The veins within the spleen that drain blood from the sinuses of the pulp and unite at the hilum to form the splenic vein. 